\title{
ENTREVISTA COM MARIA DA GLÓRIA BORDINI
}

\section{Fale um pouco sobre sua opçáo pelas Letras como área de formação.}

Quando estudante no antigo ginásio, desenvolvi certo gosto pela língua inglesa. Não a trabalhei no ensino médio, pois cursei Magistério e no currículo não havia línguas estrangeiras. Ao chegar à época do vestibular, que então não era integrado, queria me inscrever em Artes Visuais, área que me atraía, mas as Letras também eram a oportunidade para continuar o inglês. Cheguei a fazer um cursinho no Instituto de Artes, mas, ao ter de optar entre os dois cursos, pois os exames coincidiram, preferi as Letras, pensando que como artista plástica não conseguiria me sustentar.

\section{Quando e como se deu seu afastamento da UFRGS, por força do AI-5?}

Fui expurgada da UFRGS em 1969, em outubro, porque assinei um manifesto coletivo ao Reitor Faracco, protestando contra o expurgo anterior do meu professor titular, Angelo Ricci, com quem trabalhava como professorauxiliar e do professor Gerd A. Bornheim, com quem colaborava no antigo Centro de Arte Dramática, hoje DAD. Eu havia sido convidada a atuar em Teoria da Literatura e Crítica Literária, no Curso de Letras da Faculdade de Filosofia, Ciências e Letras, no início do ano letivo, recém graduada (a formatura ocorreu em março de 1968), e também em Literatura Dramática e História do Teatro. Aqueles que assinaram o manifesto foram chamados ante o interventor do governo militar e tiveram a oportunidade de se retratarem, mas eu me recusei. Por força do AI-5, fui aposentada compulsoriamente do Magistério Estadual, onde era concursada, e impedida de lecionar em qualquer instituição de ensino, federal, estadual ou municipal que recebesse incentivos do governo.

\section{O quanto o trabalho na Editora Globo ajudou para superar os graves impasses advindos, na época, do campo político?}

Depois do expurgo, todo o grupo de Letras que havia sido atingido uniuse para evitar novas perseguiçóes. Graças a uma rede de influência política à qual recorremos (lembro do apoio de Brito Velho), a nossa colaboração já existente com a Editora Globo e à amizade de Erico Verissimo, meu colega e amigo, Professor Dionísio de Oliveira Toledo, também expurgado, encaminhou-me a José Otávio Bertaso, que eu já conhecia - estávamos publicando com ele a coleçáo de Teoria da Literatura inaugurada pelos 
Formalistas Russos - e este me contratou como secretária pessoal. Ali, em virtude do prestígio da Globo, fiquei abrigada e segura durante todo o período ditatorial. Soube depois que Henrique Bertaso, presidente da Editora, receava ter uma "comunista" entre seus colaboradores, mas José Otávio Bertaso o dissuadiu do meu possível esquerdismo, e o apoio de Erico foi essencial no caso. Percorri todos os cargos ligados à edição de livros, chegando à Secretária Editorial e saí apenas quando a Editora se transferiu para o Rio de Janeiro e eu já havia sido anistiada.

\section{E a sua entrada na PUCRS, como seu deu?}

Assim que fui anistiada, voltei a trabalhar no ensino estadual, no colégio D. Diogo de Souza, no curso noturno. Fui convidada pela FAPA para lecionar na graduação, em Crítica Literária, e Regina Zilberman, que fora minha aluna na UFRGS e, depois do expurgo, me incentivara a continuar estudando, requisitou-me do Estado para cooperar com ela na área de pesquisa do Curso de Pós-Graduação em Letras da PUCRS, em que ela ingressara voltando da Alemanha já doutora. Logo depois da anistia, ela me convenceu a cursar o mestrado da PUCRS, que tinha disciplinas intensivas, o que me permitia trabalhar na Globo e fazer o mestrado nas férias. Assim que obtive o grau de Mestre, passei a lecionar na pós-graduação, além de continuar na pesquisa. Ao me aposentar da UFRGS, para onde também havia voltado, fui contratada em tempo integral pela PUCRS.

\section{NA PUCRS, você coordenou o Centro de Memória Literária e organizou cinco ediçóes dos Encontros Nacionais de Acervos Literários Brasileiros. Que balanço você faz dessas atividades? O Acervo Literário de Erico Verissimo foi um marco para os projetos de acervos no Rio Grande do Sul? Fale um pouco dessa experiência.}

O Centro de Memória Literária se deve principalmente ao espírito empreendedor de Regina Zilberman. A viúva de Erico, Mafalda Verissimo, havia me pedido para organizar os papéis do marido, e Regina viu ali a possibilidade de uma nova área de pesquisa, a de acervos. Tendo o projeto do Acervo Literário de Erico Verissimo (ALEV) sido aprovado pelo CNPq, a ideia foi se ampliando, o sistema de gestáo do ALEV se tornou modelar, outros herdeiros se interessaram em confiar seus espólios a nós e surgiu o Centro. Tratamos náo só de preservar os documentos, mas de difundir a memória literária dos autores, o que tornou nossa atividade reconhecida não só na comunidade local, mas em todo o Brasil. Foi assim que, ao lançarmos a ideia dos Encontros Nacionais de Acervos Literários Brasileiros, houve 
franca acolhida de todos os centros de documentação do País, não só os interessados em literatura, e foi possível produzir e ampliar o conhecimento nesse campo, que ultrapassava o meramente arquivístico até então vigente. O Centro foi desestruturado com nossa demissão pela PUCRS, minha e da Regina, em parte sobreviveu com outro nome, mas a área de acervos literários cresceu e prosperou no país inteiro.

Voltando à questáo editorial: dirigir as coleçóes infanto-juvenis da L\&PM Editores (de 1981 a 1990) ajudou na sua reflexáo acadêmica sobre este universo da produçáo literária? Em que sentido?

Comecei a trabalhar com literatura infanto-juvenil logo que ingressei na PUCRS, estimulada pela Regina. Era um campo aberto, pouquíssimo explorado academicamente, e ela trouxera da Alemanha o que havia de mais inovador, como a Estética da Recepçáo. Seu empenho em dar status científico à área resultou muito bem, as universidades passaram a dar atenção à produção literária para crianças e jovens e isso se refletiu nos cursos de magistério e pedagogia, de modo que pesquisas sobre leitura e literatura infantil foram progressivamente se implementando e alargando. A L\&PM se interessou pelo meu conhecimento nesse campo e convidou-me a dirigir sua coleção infanto-juvenil. A seleçáo de autores e ilustradores ficou a meu cargo e tivemos bastante sucesso, com vários títulos sendo escolhidos para os programas do MEC de incentivo à leitura. Portanto, primeiro veio a reflexão acadêmica, depois a prática editorial.

Você tem refletido sobre os desdobramentos que a internet e os meios eletrônicos trazem para a problemática da formaçáo do leitor? Como vê a questáo hoje em dia?

O problema da formação do leitor se inicia em um nível muito mais primário do que o dos meios eletrônicos. Está numa opção equivocada quanto à alfabetizaçáo e à leitura escolar, produzindo alunos que, depois de dois anos de escolarização, ainda não sabem ler. E chegam à Universidade com prejuízos enormes, que se refletem sobre seu desempenho e futura atuação profissional em todas as áreas. Não é assim que o País poderá se desenvolver - e já está provado que todos podem aprender, sejam quais forem suas condiçôes socioeconômicas. A questão é a escola, os professores e os gestores educacionais mudarem do eixo da hipocrisia e da pretensa inclusão para o da real qualificação. A expansão da internet só trouxe mais um veículo para os textos escritos, um veículo imensamente poderoso e abrangente que os jovens têm explorado para seu prazer, mas que pode democratizar todo o 
conhecimento e atingir os recantos mais remotos e destituídos. A questáo é que procuramos nela só o que nos acomoda e fugimos do que dá trabalho. Para formarem-se leitores, requer-se uma mudança de atitude quanto ao valor do trabalho, da autodisciplina, dos bens culturais. Nenhum leitor se forma sem estar interessado em ler e sem esforçar-se para tanto. Matéria de leitura há muita em circulação. O que falta é buscá-la e ultrapassar os próprios horizontes, com informação e discriminação do que é válido para cada vida.

\section{Como especialista de Erico Verissimo - cuja obra constitui tema permanente de sua carreira - como você vê o estágio atual da fortuna crítica sobre o autor?}

Quando o ALEV começou a atuar, havia alguma crítica de jornal, alguns livros sobre a obra de Erico, normalmente da época de sua geração, mas poucos estudos significativos e raros realmente acadêmicos. A dissertação de Flávio Loureiro Chaves, publicada em livro pela Globo, marcou uma reviravolta nesse contexto, complementada pela coletânea que ele organizou com a nova crítica dos anos 70 . Hoje tem aparecido uma nova geração de mestres e doutores com dissertaçóes e teses de peso sobre sua produção literária, tanto aqui quanto no exterior. O ALEV teve alguma participação nessa escalada, incentivando a consulta a fontes, em geral, inéditas e sugerindo caminhos para a renovação das leituras de Erico. Há, entretanto, muito a explorar sobre a obra de Erico, que sofreu por longos anos uma espécie de ostracismo entre certos críticos, inclusive universitários, que o viam como superficial ou alienado. As atitudes estáo menos preconceituosas e surgiram trabalhos orientados pelas correntes críticas mais atuais, revelando valores antes despercebidos em sua ficção.

\section{A transferência do ALEV para o Instituto Moreira Salles, no Rio de Janeiro, foi bom para o Erico e ruim para o Rio Grande do Sul? Ou todos perderam?}

O Acervo de Erico foi transferido para o Instituto Moreira Salles (IMS) porque o Rio Grande do Sul não ofereceu melhores condiçóes para a preservação de seu legado, especialmente porque náo temos tecnologia de restauração e de difusão na escala necessária (nem na Universidade) e porque a gestão do Centro Cultural CEEE/Erico Verissimo, entregue ao governo, acabaria sendo política, com as consequências conhecidas em tais circunstâncias. No IMS, o Acervo está muito bem cuidado e não há obstáculos à pesquisa. A centralidade do Rio de Janeiro, diminuindo 
distâncias, despertou a atenção de vários estudiosos que ali encontraram acesso mais fácil para realizarem seus projetos. Ainda está em andamento a digitalização e difusão pela internet dos documentos, mas, quando forem concluídas, Erico estará disponível worldwide. Nesse sentido, foi a melhor solução para manter a memória de Erico junto ao público e não há prejuízo para o Rio Grande do Sul, uma vez que nada impede que se procure o Acervo. Além disso, em Cruz Alta, há o Museu-Fundação Casa de Erico Verissimo, com um prédio histórico e um acervo bastante rico que, bem gerido, poderia tornar-se um polo cultural e turístico dos mais procurados, desenvolvendo a regiáo e honrando o Estado.

Você sempre foi muito respeitada como professora de Teoria da Literatura e tem uma obra paradigmática nesse campo que trata da fenomenologia da literatura pelo viés dos estudos de Edmund Husserl e Roman Ingarden. Nos estudos literários, atualmente, qual é mesmo o lugar da teoria?

Não se podem realizar estudos literários sem uma rede conceitual que direcione a crítica, a história literária, os comparativismos, os estudos culturais ou pós-coloniais. Não há como se aproximar da literatura em plena inocência. As teorias, desconcertantemente, náo são estáveis - dependem da produção e da recepção reais de cada época, do contexto sócio-histórico e de como a relaçáo entre esses é pensada -, mas sua vigência permanece enquanto produzem interpretaçóes aceitáveis. Não fosse assim, a Poética de Aristóteles teria sido esquecida há séculos. A teoria é pensamento, especulação, reflexão, e cada época faz nascer a sua, sobre a tradição já existente e as necessidades novas do tempo. Não vejo como, hoje, com todo o acúmulo de conhecimento teórico sobre literatura, alguém consiga propor a inovação absoluta: o que temos são ajustes, superposições, correções de rumo, diálogos com áreas afins, metamorfoses. Mas não se pode falar em "morte da teoria". A própria literatura tem se voltado teoricamente sobre si mesma, como os textos pós-modernos evidenciam. O que não se pode é rejeitar o pensamento, pois só a fruição não basta - esgota-se em si mesma, como todos os prazeres.

\section{Conte-nos um pouco sobre seus projetos atuais e futuros.}

Minha condição de aposentada da UFRGS me permite colaborar com a Universidade (enquanto ela quiser) num regime bem confortável - e me faculta o essencial para que minha mente não naufrague na inércia e na desmemória. Continuo lecionando em nível de pós-graduação, uma vez que 
o contato com o aluno é vital para mim. Meus alunos me obrigam a estudar sempre, a propor novas temáticas e abordagens, e isso é o grande prazer de ser professor - além do que nos divertimos bastante. Não descuido do Acervo do Erico, uma vez que a família Verissimo o tem confiado a mim desde o início, assim como náo pretendo abandonar a editoria da revista Brasil/Brazil, que publicamos com a Brown University e agora passará a ser online na UFRGS. Estou iniciando uma pesquisa sobre poesia contemporânea em língua portuguesa, que irá formar um banco de textos sobre poetas de qualidade, acessível a quem gostaria de ler sobre esses autores, conhecer alguns de seus poemas ou ensinar poesia nas escolas. Afinal, a poesia em Portugal, no Brasil e nas ex-colônias portuguesas é de uma força e atualidade impressionantes. $\mathrm{E}$, no geral, tem poucos leitores, pois as pessoas temem não compreender textos modernos e pós-modernos. A ideia é ajudar, com críticas e resenhas, o leitor interessado. E, por fim, quero escrever mais artigos e alguns livros, cumprindo promessas àqueles meus alunos que gostariam de ter meus cursos à disposiçáo, especialmente os de Poética. Estou, no momento, preparando a publicação de meus ensaios sobre acervos.

Entrevista realizada no primeiro semestre de 2015. Entrevistador: Pedro Brum Santos (UFSM). 